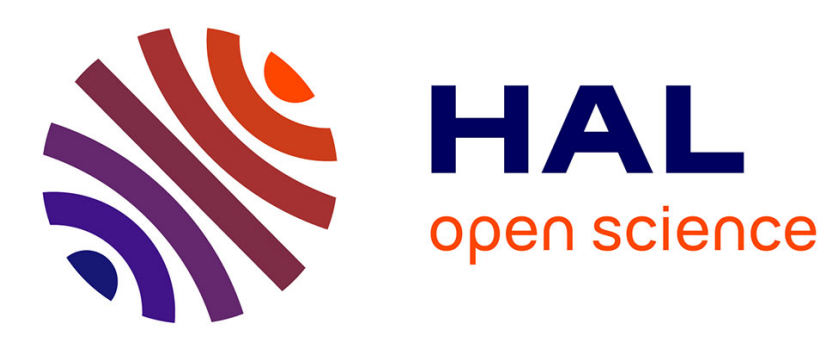

\title{
Knowledge sharability in cross-organizational collaboration: an exploratory field study
}

Imed Boughzala, Robert O. Briggs

\section{To cite this version:}

Imed Boughzala, Robert O. Briggs. Knowledge sharability in cross-organizational collaboration: an exploratory field study. HICSS 2011 : 44th Hawaii International Conference on System Sciences, Jan 2011, Kauai, Hawaii, United States. pp.1 - 10, 10.1109/HICSS.2011.275 hal-02415536

\section{HAL Id: hal-02415536 \\ https://hal.science/hal-02415536}

Submitted on 17 Dec 2019

HAL is a multi-disciplinary open access archive for the deposit and dissemination of scientific research documents, whether they are published or not. The documents may come from teaching and research institutions in France or abroad, or from public or private research centers.
L'archive ouverte pluridisciplinaire HAL, est destinée au dépôt et à la diffusion de documents scientifiques de niveau recherche, publiés ou non, émanant des établissements d'enseignement et de recherche français ou étrangers, des laboratoires publics ou privés. 


\section{Knowledge Sharability in Cross-organizational Collaboration: An Exploratory Field Study}

\author{
Imed Boughzala \\ Department of Information Systems, \\ TELECOM Business School, France. \\ Imed.Boughzala@it-sudparis.eu
}

\author{
Robert O. Briggs \\ Center for Collaboration Science, \\ University of Nebraska at Omaha \\ rbriggs@mail.unomaha.edu
}

\begin{abstract}
Collaborators on cross-disciplinary, crossorganizational teams must decide what knowledge is sharable. The sharability of a set of private knowledge is defined as the degree to which one feels willing to reveal that knowledge to people who are not members of one's own organizational unit. This paper proposes a Value Frequency Model of Knowledge Sharing (VFKS) to explain knowledge sharability and sharing. It reports qualitative findings from an exploratory field study of the degree to which constructs and relationships proposed by the model were consistent with the attitudes, opinions, and reported actions of professional Chief Knowledge Management Officers (CKMO) from 16 organizations in France. CKMO's were consistent with most aspects of the model, suggesting quantitative investigation of the model may be useful. Critical incidents and utterances of the CKMO's did not address two constructs in the model during this study. Further investigation may show whether these effects manifest in other contexts.
\end{abstract}

\section{Introduction}

The current socio-economic environment in which organizations operate is dynamic, complex and competitive. To survive, many organizations now form strategic alliances and partnerships [7]; [11]; [18]. With the globalization of markets, many of these collaborative efforts involve distributed virtual teams that span inter-organizational [14]; [9] and crossorganizational boundaries [3]. These teams form because, in the knowledge economy, organizations often face problems sufficiently complex that no single person has sufficient expertise and resources to achieve the task alone [9], giving rise to a need for crossdisciplinary teams [21]. Supply Chain collaborations [29] and outsourcing activities [19] are good examples of this kind of collaboration. Cross-disciplinary, crossorganizational collaboration inevitably leads to circumstances where collaborators must consider sharing confidential knowledge in order to move the group toward its goals [12]; [17]; [22]. At that point, a team member may deem the knowledge to be sharable or unsharable.

We define the sharability of an individual's knowledge as the degree to which that individual feels willing to share that knowledge with people who are not members of one's own organizational unit. An upstream supply chain partner, for example, may know that expected shipments to the downstream partner will be delayed because the upstream partner is having credit difficulties. The upstream partner may be willing to reveal the expected delay (high sharability), but may not want to reveal the credit difficulties (low sharability). Knowledge Sharability (KS) has two objects - the private knowledge one considers sharing and the person or people with whom one contemplates sharing it. Knowledge Sharing is an attitude involving beliefs, feelings, values and dispositions to share particular knowledge with particular people. An attitude is a mental position, feeling, or emotion with respect to a fact or state [35].

The unit of analysis for Knowledge Sharability is the individual, because sharability is an attitude formed by an individual. Knowledge sharability issues typically manifest in an organizational setting, because until an individual is a member of an in-group, the question of what can be shared with outsiders cannot arise. The organization, however, is not the unit of analysis for sharability, because the individual, not the organization, forms the attitude.

Knowledge is an intangible asset with economic value [27]; [33], and a strategic resource for creating a competitive advantage [15]; [24]; [30]. Knowledge sharing is therefore an important consideration for cross-organizational teams [25]; [26]; [29]. Knowledge sharing can be a critical success factor for collaboration and innovation [15]. Knowledge sharing is important for developing skills and competencies in organizations [31] and significantly contributes to organizational performance [5]. It is therefore important to develop better understanding of knowledge sharing. We will argue that knowledge sharing is directly influenced by 
perceptions of knowledge sharability. A better understanding of knowledge sharability could inform the development of better work practices for crossdisciplinary teams. Better techniques for reflecting on sharability could yield deliberate, rather than unexamined knowledge-sharing choices. A better understanding of sharability could be useful for remediating barriers to knowledge sharing that, in turn, could yield more successful collaborative efforts.

Many studies examine knowledge sharing in terms of attitudes and aptitudes. Individual perceptions of knowledge sharability [10], have been shown to correlate with a number of factors, among them: intrinsic and extrinsic motivation [26]; awareness of conflict of interest or vulnerability [4]; physical capability to share [6], and certain personality traits including self-interest and investment and a personal disposition to knowledge sharing [23]. Other studies consider knowledge sharing as a management process for learning and sharing understanding, sometimes supported by information and communication technologies [21]. To date, however, no general model of knowledge sharability has been advanced.

In this paper, we propose a Value Frequency Model of Knowledge Sharing (VFKS) (Figure 1), to explain knowledge sharability as an attitude that may affect knowledge sharing. The model considers antecedents of the attitude rather than the process of knowledge sharing. It seeks to account for correlations reported by earlier researchers. We synthesize the model from earlier theories from other literatures that propose explanations for intention and action. We then conduct an exploratory field study to compare the constructs and relationships proposed by the model with the attitudes, opinions, and reported actions of professional Chief Knowledge Management Officers (CKMO) from 16 organizations in France.

\section{A Value Frequency Model of Knowledge Sharability and Knowledge Sharing}

Expectancy Value Theories (EVT) of motivation [34] and theories that build upon them may provide a useful theoretical foundation for understanding perceptions of knowledge sharability and its relationship to the actual knowledge sharing. In expectancy value theories, an expectancy is defined as a projection of the likely outcomes of a contemplated action, and a value is a perception of the degree to which the projected outcomes would be instrumental or detrimental to one's interests [28]; [32]; [34]. These theories posit that motivation for a contemplated action is a function of expectancy value. The more positive the value ascribed to an expectancy the more motivated one will be to act. The more negative the value ascribed to an expectancy, the more demotivated one will be to act.

In the context of this study, the action of interest is knowledge sharing. Like EVT's VFKS assumes that:

Assumption $1 . \quad$ Sharing Outcome
Projection: An automatic, subconscious
mechanism of the mind projects the likely
consequences of sharing knowledge.

Assumption 2. Value of Expected Outcomes: An automatic, subconscious mechanism of the mind ascribes some value (positive or negative) to projected outcomes of sharing.

Assumption 3. Knowledge Sharability. A automatic, subconscious mechanism of the mind derives a sharability attitude (positive or negative) with respect to sharing particular knowledge that is proportional to value of expected outcomes of sharing.

The Value Frequency Model of Willingness to Change Work Practices (VFM), a domain-specific instantiation of EVT in the IS literature, proposes six dimensions along which people may perceive value: economic, political, social, cognitive, affective, and physical. VFKS likewise assumes that:

Assumption 4: Dimensions of Value. Value judgments may pertain to any or all of the economic, political, social, cognitive, affective, and physical dimensions of value.

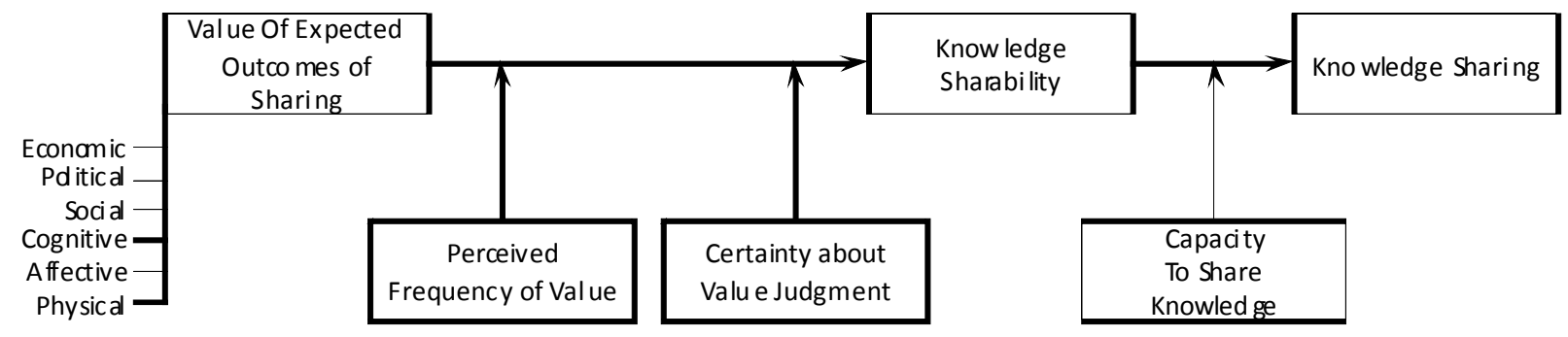

Figure 1. A Valu e Frequen cy M odel of Kn owl edge Sh aring 
Reasons theories (RT) of motivation build on EVTs [1]; [2]; [34] by proposing that the relationship between attitude and action is mediated by intention. Analogous to RTs, VFKS proposes Knowledge Sharability as a mediator between Value attitudes and Knowledge Sharing actions. It further proposes that the sharabilitysharing relationship must be moderated by Capacity to Share. An intention to act can only be carried out if actors are capable of executing the intended action. Issues of aptitude, ability, and/or access could prevent knowledge sharing even if sharability were positive.

VFKS draws on EVTs further by assuming automatic, subconscious mechanisms of the mind assess the frequency with which one might obtain value from expected outcomes, and proposes that perceptions of Frequency of Value would moderate the valuesharability relationship. The larger the magnitude of the frequency perception, the larger would be the effect of Value perceptions on Knowledge Sharability. VFKS, like VFM, also posits that intentions may be affected by the degree of certainty people ascribe to their judgments. VFKS therefore proposes that the valuesharability relationship is moderated by Certainty about Value Judgments.

\section{An Exploratory Field Study of Knowledge Sharability}

Using VFKS as a guiding framework, we conducted an exploratory field study of Knowledge Sharability among Chief Knowledge Management Officers (CKMOs) from organizations in France. There were several research questions:

R1: To what extent does value of expected outcomes correlate with knowledge sharability

R2: To what extent is the value-sharability relationship moderated by perceived frequency of value?

R3: To what extent does certainty about judgments moderate the value-frequency relationship?

R4: To what extent does capacity-to-share moderate the relationship between sharability and sharing?

\subsection{Participants}

A total of 16 CKMOs and 4 surrogates participated in the four focus groups. A minimum of 14 and a maximum of 16 experts were present at each of the four meetings. In four cases, a CKMO sent a surrogate to a meeting. The involvement of experts in focus groups [20] allowed us, in the words of Hevner et al. [16] p. 80 ), "to combine relevance and rigor by meeting a business need with applicable knowledge." Each CKMO worked for a different company. Companies were in various sectors, including Automotive, Software, Audiovisual, Civil Engineering, and Telecommunications. Companies ranged in size from approximately 1,000 to 200,000 employees. Ten were multinational firms. The names of the companies were withheld to protect their privacy, but companies are identified by their sector. The names of CKMOs were likewise withheld for privacy reasons. Statements by participants were identified only by the industry sector in which they worked.

All participants held master degrees (MSc or MBA), and four had earned Ph.D.s. Their degrees were in a variety of disciplines: Industrial Design, Mechanical Engineering, Human Resources, Management, Computer Science and Ergonomics. Their work experience ranged from 15 to 34 years. Half the participants had more than five years experience as a CKMO. The average age of CKMOs was 47 and $68 \%$ were male. All of the participants were French by birth. All sessions were conducted in French.

\subsection{Procedures}

Participants met in four focus groups over a four-month period between November 2007 and February 2008 to gather insights about knowledge sharability issues from $\mathrm{KM}$ and collaboration experts. The focus groups took place during four consecutive regularly scheduled meetings of a professional business association for CKMOs. Focus groups were conducted by one of the authors. Recording devises were not allowed in the sessions. A graduate assistant recorded all sessions and made field notes about critical incidents and oral statements during meetings. Participants recorded their key contributions on Post-it notes, and gave them to the research team at the end of each session. The moderator made field notes immediately following every session.

To minimize the possibility of biasing the observations, we did not seed the focus groups with questions pertaining to the model. Rather, we observed and documented interactions among subjects who were already deeply interested in issues of knowledge sharability, and who were motivated to discuss it by issues they experienced in the workplace. The participants devised their own goals and their own questions created deliverables of their own design during these sessions. The researchers who observed and documented the sessions were not briefed on the 
model until after the sessions were over. After the sessions, the observers were briefed on the model, and were asked to code their observations in terms of the constructs of the model.

\subsection{Focus Group Process}

Focus groups were announced with the theme "KM and Collaboration." Each session focused on a different aspect of Knowledge Sharability (KS) as a success factor in cross-organizational collaboration. In these meetings participants were to a) brainstorm on antecedents of knowledge sharability; b) brainstorm on conditions for successful knowledge sharing processes; c) build a preliminary questionnaire, which came to be called the Knowledge Sharability Grid, to assess knowledge sharability on the ground; and d) build a framework for better understanding of knowledge sharing among companies.

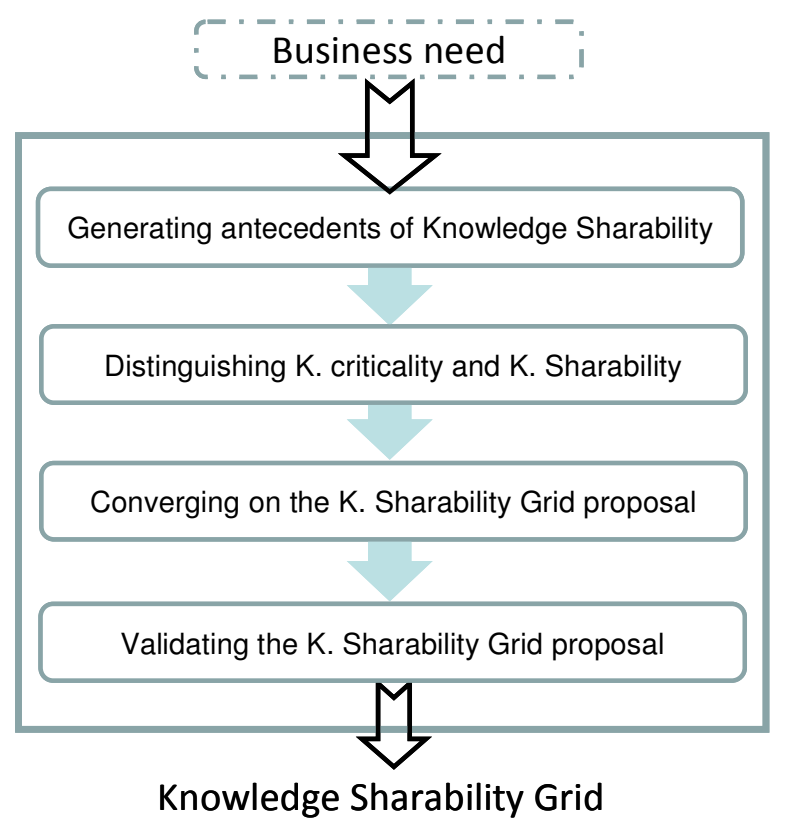

Figure 2. The Topics of Four Successive Focus Groups with 16 CKMOs to Develop Understandings of Knowledge Sharing.

Each meeting was held at a different site volunteered by one of the CKMO participants. Tables and chairs were arranged in a $U$ shape so participants could make eye contact. Each session opened with a presentation by an outside expert about some aspect of information/knowledge sharing and crossorganizational collaboration from professional and research perspectives. Participants then participated in a one-hour session to generate, clarify, organize, evaluate, and reduce a set of ideas about Knowledge Sharing.

At the beginning of each interactive session, participants received these guidelines:

- All members should read the minutes of the previous meeting.

- The group should focus/concentrate its work only on the knowledge sharing-sharability concerns.

- Members should respect the time fixed by the facilitator (the researcher) for each activity.

- Members should write their ideas on Post-it notes before sharing them with the group.

- They should argue/justify each of their ideas by giving practical examples.

Figure 2 summarizes topics of the four working meetings as the focus group process steps.

The final deliverable from the four sessions was a questionnaire instrument that the participants came to call the Knowledge Sharability Grid. Each focus group built on the results of the previous focus group's session.

\subsection{Session Details}

Each session had a different goal and a different work practice.

\subsubsection{Session 1}

An IT Consulting Firm hosted the first session in November 2007. Participants were asked to brainstorm possible antecedents of Knowledge Sharing and Knowledge Sharability in cross-organizational collaboration. Participants used a directed brainstorming technique. The brainstorming responded to these questions:

- What kind of knowledge could be shared in crossorganizational collaboration?

- What could increase the willingness to share?

- What makes some people share more than others?

- What is knowledge sharability?

- What are its characteristics?

- Why is it important for companies?

- When does it become critical?

\subsubsection{Session 2}

An Audiovisual \& Communication Firm hosted the second session in December 2007. The focus of this session was to distinguish between Knowledge Criticality [13] and Knowledge Sharability. In sessions predating this study, the association had worked on 
defining Knowledge Criticality, which they had defined as the degree to which a knowledge domain was critical to an organization's success. In this meeting, the distinction between knowledge criticality and knowledge sharability was clarified. At the end of the session, the group agreed that knowledge criticality is the degree to which the sharing of a knowledge set held by a group (organizational unit, organization or group of partners) with outsiders would make the knowledge holders vulnerable. The group determined, however, that criticality was not sufficient to explain sharability of knowledge within a group. Knowledge Criticality was deemed a group phenomenon, while Knowledge Sharability was deemed an individual phenomenon. The group decided to consider Knowledge Sharability according to three points of view:

- The knowledge itself: Does the individual deem the knowledge sharable, given the risk it may impose? Is the individual willing to share?

- The agent: Is the agent capable of sharing? Can the knowledge be made explicit? Should it be? What could happen?

- The group: Will sharing knowledge serve business objectives or enhance crossorganizational collaboration? What makes the group willing to sharing knowledge? What are the risks?

\subsubsection{Session 3}

The third session occurred in January 2008 at a Transport \& Freight Firm. The goal was to generate criteria by which people judged knowledge sharability from three perspectives: The individual, the group to which an individual belongs, and the partners with whom the group collaborates. The group was divided into three subgroups of five or six CKMOs, each from a different industry. Each subgroup brainstormed for an hour to compile a list of criteria for one of the three points of view: knowledge, agent, and group. Groups then rejoined and worked for 2 hours to consolidate their concepts into 18 criteria, which they organized into an array they dubbed the Sharability Grid.

\subsubsection{Session 4}

The fourth meeting in February 2008 occurred at a Telecommunications Firm. The goal was to validate the KS Grid.
From the knowledge point of view:

Explicitness: To what extent could this knowledge be made explicit or be elicited?

Usefulness: Is this knowledge useful for group collaboration?

Responsiveness: Does sharing this knowledge improve responsiveness within the group?

Effectiveness: Does sharing this knowledge make collaboration more effective?

Quality: Is the knowledge of sufficient quality to be shared? What are the criteria for judging quality?

Added Value: Does this knowledge allow value creation?

From the agent point of view:

Substantiality: Is this knowledge substantial to the agent i.e., important to his/her core business?

Confidentiality: To what extent must the agent keep this knowledge confidential (e.g. trade secret, fiduciary responsibility, etc.)?

Reusability/Reuse: To what extent can this knowledge be reused?

Subsidiarity: Is there other knowledge that can be substituted for this knowledge in this collaboration?

Transferability: To what extent is this knowledge transferable?

Frequency of Value: How often could this knowledge be a source of value?

From the group point of view:

Autonomy: Does the sharing of this knowledge affect the autonomy/independence of the agent in the group?

Vulnerability/Risk: Does the sharing of this knowledge make the agent vulnerable in the group (from a strategic point of view, current place in the group, over time, etc.)?

Shared Values: What are the moral values that govern the group and that protect the knowledge (deontology, ethics, intellectual integrity/property, etc)?

Incentive Policy/Motivation: What could encourage the agent to share this knowledge with others? What could (s)he expect in an exchange (i.e. expectancy) or what does this knowledge bring to the group (i.e. value)?

Table 1. Knowledge Sharability Grid: An Instrument for Evaluating the Sharability of Knowledge.

This grid was derived by a group of 16 CKMOs during a series of four expert focus groups. 
The objective was to make sure that there was no redundancy among criteria, and to assure that the set was sufficiently comprehensive to address the antecedents and criteria they had generated in earlier sessions. Sixteen criteria were retained; two were eliminated. Then, the group drafted one question for each remaining criterion. Table 1 presents the Knowledge Sharability Grid. It is offered here to clarify the work the participants did during their focus group.

\subsection{Analysis Methods}

The moderator and the graduate assistant, native French speakers, transcribed Post-its and field notes into a collection of utterances identified by contributor. They then anonymized the transcript. The moderator/researcher then coded the French-language utterances according to the concepts of VFKS. The transcripts were then translated into English and validated by a native English speaker. An Englishspeaking researcher then coded the utterances according to the concepts of VFKS. Coders had substantial concurrence.

\section{Analysis of Session Transcripts in Light of VFKS}

This section presents an analysis of the session transcripts in light of the constructs and relationships proposed by VFKS. Many of the utterances from the CKMO participants about knowledge sharing and sharability were consistent with the constructs and relationships proposed by VFKS. This section presents qualitative evidence to support that assertion.

\subsection{Value of Expected Outcomes of Sharing}

The CKMOs ascribed value to knowledge:

- "Knowledge is an intangible asset that has an economic value" (R\&D CKMO)

- "Having experience in a situation will not make you sure to solve the problem, but it gives you an advantage" (IT consulting CKMO)

- "Knowledge is often considered as power" (R\&D CKMO)

- "Knowledge is a strategic asset and a competitive advantage for companies on the market" (Automotive CKMO)

- "Knowledge is a strategic resource of productivity" (R\&D CKMO)

\subsection{The Value-Sharability Relationship}

The CKMOs asserted that the outcomes of Knowledge Sharing could have positive economic, political, social, or cognitive value that motivated people to share knowledge:

- "Using social computing, experts can find each other more easily and collaborations start with a few clicks" (IT Consulting CKMO)

- "With the complementarily of knowledge and experiences, the problem-solving become easier" (R\&D CKMO)

- $\quad$ Sometimes we spend a lot time trying to find good knowledge, and we have to ask for external help, while the guys in the back office already had it ... so we lose time and money..." (IT Consulting CKMO)

- "Sharing knowledge enhance the capability of firms to perform and to respond to client demands" (Telecoms CKMO)

They stated that knowledge sharing could also produce negative outcomes that threaten the long term viability of the organization, reducing motivation to share knowledge:

- "We can outsource everything...only our core business knowledge capital has to be preserved...it is our existence" (Aeronautic CKMO)

- "Imitation is our big problem, comes from all the world” (Automotive CKMO)

- "Some believe that when sharing, they lose their importance in the group ...it is an old myth of the old generation of computer scientists" (Software edition CKMO)

- "A partner with whom we share today could become a competitor tomorrow. This sharing allows may be to increase the short-term value of a service or a product which we create, but may be with means and long terms a source of loss" (Aeronautic CKMO)

- "Sharing efforts are seen as a kind of volunteer action impinging on the performance of their daily tasks. A more explicit recognition should be putted in place" (Transport CKMO)

- "Working transparently with others reduces their and our autonomy” (Transport CKMO)

The CKMOs appear to assume a close association between value and sharability by trying to motivate knowledge sharing with intrinsic and extrinsic rewards: 
- "We try to find more tangible rewards to promote that (peer recognition, financial, etc.) (Civil eng CKMO)

- "Peer recognition is more important in our field" (Automotive CKMO)

- "Lack of time and recognition from Top management is widely cited as barriers to knowledge sharing” ( $R \& D$

- "With all the efforts we did, their attitudes toward sharing knowledge seem to remain unchanged" ( $R \& D C K M O)$

- "The more a firm is revealed in a extended enterprise, the more she loses its independency towards others partners" (Aeronautic CKMO)

Sometimes both positive and negative value can arise from the same knowledge-sharing event, giving rise to conflicting interests that must be resolved:

- - "In our field/activity, there is a contradiction/paradox: sharing knowledge is rewarded-keeping knowledge is advised to keep you self competitive on the market" (IT consulting CKMO)

\subsection{Frequency Moderation of Value - Sharability Relationship}

Participating CKMOs did not make any comments with respect to the degree to which perceived frequency of value moderates the Value-Sharability relationship posited by VFKS.

\subsection{Certainty Moderation of the Value- Sharability Relationship}

VFKS posits that the Value-Sharability relationship may be moderated by the degree to which people feel certain that they will attain the value they perceive in a knowledge-sharing opportunity. Evidence of such a moderating relationship emerged in the CKMO discussions of goodwill, trust, vulnerability, and risk.

- "Knowledge sharing relies on the goodwill of people when there is no conflict of interest ... it is based on ad hoc initiatives" (IT consulting CKMO)

- "Collaboration requires trust ... but when it is question to share their knowledge, people feel like dispossessed. A basic survival instinct arises to protect themselves" (IT consulting CKMO)
- "Vulnerability is a criterion of sharability...when someone feels vulnerable, (s)he does not share to protect him/her self" (Energy CKMO)

- "The vulnerability of the organization is linked to the vulnerability of its knowledge" (R\&D CKMO)

- "It depends on people. There are who they have the habit of taking without giving" (IT consulting CKMO)

- "Criticality and sharability are linked. If I do not share my knowledge because I believe that is critical ... doing that is risky" (Aeronautic CKMO)

- "A partner with whom we share today could become a competitor tomorrow. This sharing allows may be to increase the short-term value of a service or a product which we create, but may be with means and long terms a source of loss. "Should we speak her about Inter organizational KM?" (Aeronautic CKMO)

\subsection{The Sharability-Sharing Relationship}

The CKMOs did not comment directly on the Sharability- Sharing relationship posited by VFKS.

\subsection{Capacity Moderation of the Sharability- Sharing Relationship}

The CKMO participants made a number of statements that touched on the degree to which Capacity to Share moderated the proposed relationship between Knowledge Sharability and Knowledge Sharing.

- "These should be balanced: willingness to share and being able to do it" (Telecoms CKMO)

Some, highlighted the challenge of sharing tacit knowledge:

- "Some knowledge can never be elicited. It remains tacit in the head of experts...socialization is the best way to transfer it" (Audiovisual CKMO)

- "Before, when the work was manual, it was possible to learn by observation and imitation. Now everyone is working behind his/her own computer..."(Automotive CKMO)

- "How you can ask people to share...if they don't know that they know or what they have to share.". (Audiovisual CKMO)

Some focused on physical and cognitive barriers to sharing, or drew attention to those barriers by noting that technology could, but does not always make sharing easier: 
- "Generally people have a positive attitude in respect of knowledge sharing but in the facts they have no time..." (Transport \& freight CKMO)

- $\quad$ "Some tools are available but these resources are generally under used." (Civil eng. CKMO)

- "Before to use tools [it was hard]. It was easier in this case not to share." (Audiovisual CKMO)

- "By enabling people to share content (slides, proposals, documents, etc.) through our collaborative platform, the time we gain up to $70 \%$ in time savings...imagine what will happen now that we have wikis and blogs" (IT consulting CKMO)

Others touched on the degree to which ethical or legal constraints could constrain sharing:

- "Sometimes [knowledge remains unshared] not for a lack of willingness, but rather because of professional obligations" (Aeronautic CKMO)

- "Some knowledge can never be elicited, they remain tacit in the head of experts...socialization is the best way to transfer it" (Audiovisual CKMO

The CKOs also touched on ethical and legal constraints that could block sharing among people willing to share:

- 'Sometimes, it's not for lack of willingness but it is by professional obligations...or the damage that may result” (Aeronautic CKMO)

- "Consultants shall not speak of what they saw working for a given client. It is a pact of confidence that we have with them." (IT Consulting CKMO)

\section{Discussion of Findings and Future Directions}

This exploratory study showed that CKMO statements corresponded closely to the constructs and relationships proposed by VFKS. They did ascribe value to knowledge. They identified the possibility for both positive and negative outcomes from knowledge sharing, and asserted that these expectancies were closely associated with knowledge sharability attitudes.

The CKMOs did not directly discuss a relationship between Knowledge Sharability attitudes and Knowledge Sharing actions. They appeared to assume such a relationship, however, because they discussed the degree to which Capability to Share moderated this relationship. Further exploratory and experimental research will be required to investigate this effect.

The CKMOs said little about the degree to which perceptions of frequency moderated the value- sharability relationship. It could be that, in this sample, frequency issues did not emerge. It is also possible, though that perceptions of frequency are inextricably linked to perceptions of value. Rather than making value judgments that are moderated by frequency judgments, it may be that a cognitive mechanism synthesizes a single value-frequency judgment. Further exploratory and experimental research will be required to investigate this effect.

\subsection{Limitations}

This study has several limitations. As with all exploratory science, this paper reports, explores and describes phenomena of interest in a context where they manifest. Although it proposes a model that suggests close associations among constructs, the model is a descriptive theory. It does not yet rise to the standard of a fully realized causal theory because its relationships are not yet derived by rigorous logical arguments from axiomatic foundations. More exploratory and theoretical research will be required before a rigorous theory can be advanced to explain the effects modeled and reported in this paper. Further, it is not the role of exploratory science to assert causality, and this study does not attempt to do so. Rather, it seeks to report effects observed in the field with sufficient clarity that other researchers can add detail to the descriptions with further exploratory research, which may, in turn, inform theoretical work that can fully explain the variations in Knowledge Sharability. Finally, this paper is qualitative. Until a sound theory is advanced, it would not be possible to conduct formal experimental science, because the role of experimentation is to test theoretical propositions. Experimental techniques, however, can be a useful tool for advancing exploratory science by further quantifying and characterizing observed effects. Given the findings of this paper, it may be useful to explore VFKS more fully using quantitative methods.

\subsection{Future Directions}

The findings of this paper suggest that the model has some face validity, and so it may merit further exploratory work to gain more insights about whether and how these effects manifest in the workplace. This study drew insights only from CKMOs. It would also be useful to explore these phenomena among people collaborating at the operational level. It would also be useful at this point to conduct theoretical development of the model, laying an axiomatic foundation for its propositions, and deriving the logic to link the propositions to the axioms. Experimental research focusing on specific propositions of the model would shed further light on its scientific utility. 
This study did not garner evidence one way or the other with respect to two aspects of the model: the potential for perceived frequency to moderate the valuesharability relationship, and the sharability-sharing relationship. It would not be sound to reject the proposed relationships based on a single exploratory study. Further, focused investigation of these aspects will be required to determine whether or not these propositions hold.

\section{Conclusions}

This paper advances a Value Frequency Model of Knowledge Sharing as an explanation for variations in attitudes toward sharing knowledge with people outside one's own work group or organization. It then reports on an exploratory field study with 16 CKMOs to investigate the degree to which their experiences and understandings of Knowledge Sharability were consistent with or different from the constructs and relationships proposed by the model. Where CKMO has made statements about topics addressed by the model, their statements were consistent with the logic of the model. CKMOs, however, were silent on two aspects of the model - the Frequency construct and the direct effect of Knowledge Sharability attitudes on Knowledge Sharing behaviors. Further research will be necessary to explore these and other aspects of the model more fully.

\section{References}

[1] Ajzen I., "The theory of planned behavior", Organizational Behavior and Human Decision Processes, 1991, 50(2), 179-211.

[2] Ajzen I., and M. Fishbein, "Attitudinal and normative variables as predictors of specific behavior", Journal of Personality and Social Psychology, 27(1), 41-57, 1973.

[3] Anand V., C. C. Manz, and W. H. Glick, "An organization memory approach to information management", Academy of Management Review, 1998, 23(4), 796-809.

[4] Argote L., D.Gruenfeld, and C. Naquin, "Group learning in organizations", In M. E. Turner (Ed.), Groups at Work: Theory and Research. Mahwah NJ: Lawrence Erlbaum, 2001.

[5] Argote L., P. Ingram, J. M Levine., and Moreland R. L., "Knowledge transfer in organizations", Organisational Behavior and Human Decision Processes, 2000, 82(1), 1-8.

[6] Argote L., B. McEvily, and Reagans R., "Managing knowledge in organizations: An integrative framework and review of emerging themes", Management Science, 2003, 49(4), 571-582.

[7] Badaracco J. L., "The knowledge link - How firms compete through strategic alliances", Boston: Harvard Business School, 1991.
[8] Baratt M., "Understanding the Meaning of Collaboration in Supply Chain", Supply Chain Management: An International Journal, 2004, 9(1), p. 30-42.

[9] Boughzala I., "Methodological approach for designing interagent cooperative information systems for knowledge management" (in French). PhD Thesis, University of Paris VI, December 2001.

[10] Cabrera A., and E. F. Cabrera, "Knowledge-sharing dilemmas", Organization Studies, 23(5), 2002, 687-710.

[11] Doz, Y., and G., Hamel, "Alliance Advantage: The Art of Creating Value through Partnering", Harvard Business School Press, Boston, Massachusetts, 1998.

[12] Dyer J.H., and K. Nobeoka, "Creating and Managing a High-Performance Knowledge-Sharing Network: The Toyota Case", Strategic Management Journal, 2000, vol. 21, p. 345367.

[13] Ermine J-L., I. Boughzala, and T. Tounkara, "Critical Knowledge Map as a decision tool for knowledge transfer actions", Electronic Journal of Knowledge Management, 2006, 4( 2), pp. 129-139.

[14] Gardenswartz L., \& Rowe A. (1994). Diverse teams at work: Capitalizing on the power of diversity. New York: McGrawHill.

[15] Grant R.M., "Prospering in Dynamically-competitive Environments: Organizational Capability as Knowledge Integration", Organization Science, 1996, 7 (4), 375-387.

[16] Hevner A. R., S. T. March, J. Park, and S. Ram, "Design Science in Information Systems Research", MIS Quarterly, Vol. 28 No. 1/March 2004.

[17] Hsiao R.-L., "Knowledge Sharing in a Global Professional Service Firm”, MIS Quarterly executive, 2008, 7(3).

[18] Kanter R., "Collaborative advantage: the art of alliances”, Harvard Business Review, 1994, 72, 96-108.

[19] Kern T., and L. P. Willcocks, "Exploring information technology outsourcing relationships: Theory and practice", Journal of Strategic Information Systems, 2000, 9(4), 321350 .

[20] Kitzinger, J., "Introducing focus groups", British Medical Journal, 1995, 311, 299-302.

[21] Kluege J., Stein W., and Licht T., Knowledge Unplugged, Palgrave, Basingstoke, 2001.

[22] Koh C., Ang S., and D.W. Straub, "IT outsourcing success: A psychological contract perspective", Information System Research, 2004, 15(4), 356-373.

[23] Matzler K., B. Renzl, J. Muller, S. Herting, and T. A. Mooradian, "Personality traits and knowledge sharing", Journal of Economic Psychology, 29 (2008) 301-313.

[24] Nanda A., "Resources, capabilities and competencies", In B. Moingeon \& A. Edmonson (Eds.), Organizational learning and competitive advantage, 1996, London: Sage, pp. 93-120. 
[25] Nonaka I., "The Concept of "Ba": Building a Foundation for Knowledge Creation", California Management Review, 1998, Vol. 40, no. 3.

[26] Osterloh M., and B. S. Frey, "Motivation, knowledge transfer, and organizational forms", Organization Science, 2000, 11(5), 538-550.

[27] Penrose E., The Theory of Growth of the Firm, London: Basil Blackwell, 1959.

[28] Rosenberg M. J., "Cognitive structure and attitudinal affect", Journal of Abnormal and Social Psychology, 1956, 53(3), 367-372.

[29] Skjoett-Larsent T., Thernoe C., Andersen C. (2003), « Supply Chain Collaboration. Theoretical Perspective and Empirical Evidence », International Journal of Physical Distribution and Logistics Management, vol. 33, ${ }^{\circ}$ 6, p. 531549.

[30] Spender J.-C., "Competitive advantage from tacit knowledge?" In B. Moingeon \& A. Edmonson (Eds.),
Organizational Learning and Competitive Advantage (pp. 5673). London: Sage, 1996a.

[31] Spender J.-C., "Making knowledge the basis of a dynamic theory of the firm", Strategic Management Journal, 17(Winter special issue), 45-62, 1996b.

[32] Vroom V. H., Work and Motivation, New York, NY: Wiley, 1964.

[33] Wernerfelt B., "A resource-based view of the firm", Strategic Management Journal, 5, 2 (April-June 1984), 171180.

[34] Westaby J. D., "Identifying specific factors underlying attitudes toward change: Using multiple methods to compare expectancy-value theory to reasons theory", Journal of Applied Social Psychology, 2002, 32(5), 1083-1106.

[35] Webster.com (2010) http://www.merriamwebster.com/dictionary/attitude. Accessed 9/3/2010. 